\title{
CAPACIDAD ANTIBIOTICA DE CEPAS DE Streptomyces FRENTE A AGENTES ETIOLOGICOS DE DERMATOMICOSIS
}

\author{
A. Tresierra A. * \\ M. E. Bendayán A * * \\ M. García D. *
}

\section{RESUMEN}

Se aislaron en Agar Glutamato, 20 cepas de Streptomyces a partir de muestras de suelos agrícolas de Iquitos y se seleccionaron aquellas que presentaban alta capacidad antifúngica frente a tres agentes etiológicos de dermatomicosis (Microsporurn canis, Trichophyton mentagrophytes y Epidermophyton floccosum), mediante las técnicas de la estría en agar,. de los bloques y de los cilindros.

El 15,0\% de las cepas mostraron alta actividad antifúngica, con zonas de inhibición mayores de IOntm, pero de espectro reducido.

Palabras claves: Streptomyces, antibiosis, dermatomicosis.

\section{ABSTRACT}

Twenty strains of Streptomyces were isolated in Glutamate Agar, from agricultural soil samples of Iquitos. Those strains with high antimycotic capacity against three aetiologic agents of dermatomycosis (Microsporum canis, Trichophyton mentagrophytes and Epidermophyton floccosuni), using the groove in agar, the blocks and the cylinders tests, were selected.

Only the $15,0 \%$ of the strains showed high antimycotic activity, with inhibition zones greater of $10 \mathrm{~mm}$, but of reduced spectrum.

\section{INTRODUCCION}

El suelo constituye el ambiente que alberga a la mayoría de tipos representativos de seres microscópicos y a una gran cantidad de microecosistemas en los cuales, muchos de estos seres interactúan entre sí. Una de

* Dpto. Acad. de Microbiología. Fac. de Ciencias Biológicas-UNAP. A partado Postal 751. IQUITOS-PERU. 
estas interacciones resulta ser la antibiosis o antagonismo microbiano, cuya mayor importancia radica en la síntesis de sustancias antibióticas, Curran, (1977).

Los actinomicetos 0 bacterias ramificadas, destacan entre la flora microbiana del suelo capaz de producir antibióticos, en especial los miembros del género Streptomyces, ya que son la fuente de producción de más del 60,0\% de todos los antibióticos descritos hasta ahora y de más del $90,0 \%$ de los utilizados en terapia humana, Kuster, (1981). Esta cualidad constituye uno de los motivos que justifican su interés para el hombre y quizás, el más trascendental Kuster, (1976) y Shearer, (1987).

A ctualmente, existen en varios países, grandes laboratorios que vienen realizando intensas investigaciones, analizando diversas muestras de suelo a fin de aislar cepas más eficientes en la síntesis de antibióticos conocidos o descubrir cepas productoras de nuevas sustancias antibióticas; por otro lado, se trata de optimizar el proceso de síntesis a nivel industrial, Rautenshtein, (1966).

En base al conocimiento de que la mayoría de antibióticos de uso actual son producidos por miembros del género Streptornyces y que el principal hábitat de estos microorganismos es el suelo, en especial el suelo agrícola fértil, Küster, (1976), se planteó la posibilidad de que en los suelos agrícolas de Iquitos debería de existir una diversidad de cepas de Streptomyces, lo cual nos facilitaría realizar el aislamiento de algunas de ellas y posteriormente, realizar ensayos a fin de investigar su capacidad antibiótica frente a agentes causantes de micosis cutáneas o dermatomicosis, ya que estas enfermedades son de gran frecuencia en nuestro medio.

\section{MATERIAL Y METODOS}

\section{UBICACIÓN DE LA ZONA DE MUESTREO}

Diez muestras de suelo fueron tomadas del campo experimental de la Facultad de A gronomía-U NA P (Zungarococha: $25 \mathrm{~K} \mathrm{~m}$. al Sur-Oeste de la ciudad de Iquitos).

\section{MICROORGANISMOS DE PRUEBA}

M icrosporum canis (agente etiológico de la tiña corporis y tiña capitis).

Trichophyton mentagrophytes (agente etiológico de la tiña corporis, tiña cruris, tiña pedis, tiña manus, tiña unguium).

Epidermophyton floccosurn (agente etiológico de la tiña unguium y tilia cruris). 


\section{PROCE DIMIENTO}

Las muestras se diluyeron decimalmente hasta $10^{-5}$ con suero fisiológico, sembrando por duplicado las tres ultimas diluciones en placas con Agar Glutamato, Chávez, (1970). Estas, se incubaron a temperatura ambiente $( \pm 26,9$ oC, según el SENAMHI), durante cinco días.

Se eligieron, a simple vista, las colonias sospechosas de pertenecer al género Streptomyces y se transfirieron a tubos con Agar Nutritivo, los cuales fueron sometidos a condiciones de incubación similares a las descritas.

\section{Identificación Genérica de los Cultivos Aislados}

Se tuvieron en consideración las características morfológicas de las colonias.

\section{Estudio M acroscópico}

Los cultivos fueron sembrados en placas con A gar Glucosado, las que se incubaron a temperatura ambiente durante cinco días, luego se observaron la consistencia y el aspecto de las colonias. Según Locci, R. 1989 y Waksman, 1961, a aquellos cultivos que muestran colonias pequeñas $(1-10 \mathrm{~mm}$ de diámetro), liquenoides, coriáceas o butirosas, de superficie inicialmente lisa pero que posteriormente se vuelven granuladas, pulverulentas, aterciopeladas 0 peludas y que tienen la propiedad de adherirse al agar, se les debe someter a un estudio microscópico.

\section{Estudio M icroscópico}

Este se hizo mediante la técnica del microcultivo, utilizando Agar Glucosado, incubando a temperatura ambiente y haciendo observaciones periódicas del desarrollo, especialmente de la morfología del esporóforo. A aquellos cultivos cuyo "micelio aéreo" al madurar formaba cadenas de tres o más esporas, las cuales no nacían de esporóforos verticilados, se les identificaba como miembros del género Streptomyces.

\section{Investigación de la Capacidad Antimicótica de los Cultivos Aislados}

Se utilizaron las técnicas de la estría en agar, de los bloques y de los cilindros; considerándose con actividad antimicótica a los cultivos que ocasionaron zonas de inhibición de 10 mm a más, Waksman, (1961). 


\section{Técnica de la Estría en Agar}

Cada cultivo fue sembrado en placas con Agar Waksman en estría longitudinal (a lo largo del diámetro de la placa). Estas se incubaron a temperatura ambiente durante cinco días. Luego, perpendicularmente se sembraron los microorganismos de prueba y reincubaron durante tres días más.

La falta de crecimiento en las zonas cercanas a la estría de Streptomyces indicaba la existencia de actividad antibiótica.

\section{Técnica de los Bloques}

Bloques de A gar Waksman (de $4 \mathrm{~mm}$ de diámetro), donde previamente se habían cultivado a las cepas de Streptomyces, se colocaron sobre placas con A gar Glucosado, las que fueron sembradas anteladamente con el respectivo microorganismo de prueba $(0,1 \mathrm{ml}$ de un cultivo fúngico en Caldo Glucosado). Estas se incubaron a temperatura ambiente durante tres días.

\section{Técnica de los Cilindros}

Se aplicó solamente a las cepas que mostraron tener actividad antibiótica mediante las dos técnicas anteriores. Estas se sembraron en Caldo Waksman e incubaron a temperatura ambiente, en agitación, durante cinco días. Luego se filtraron y $0,5 \mathrm{ml}$ del filtrado de cada cultivo se colocaron en cilindros de plástico estériles ( $5 \mathrm{~mm}$ de diámetro interno), los cuales previamente fueron colocados en placas con A gar Glucosado y en las que se había sembrado el microorganismo de prueba. Se incubé a temperatura ambiente durante 72 horas.

La presencia de un halo de inhibición del crecimiento alrededor de los bloques o cilindros, indicaba la existencia de actividad antibiótica.

\section{RESULTADOS}

Se aislaron, a partir de las diez muestras de suelo, 142 colonias con apariencia de Streptomyces, de las cuales se identificó a 20 de ellas como pertenecientes a dicho género y cuyas características se muestran en el Cuadro 1: 


\section{Cuadro 1}

C aracterísticas morfológicas de las cepas de Streptomyces aisladas del suelo.

\begin{tabular}{|c|c|c|c|c|c|}
\hline $\begin{array}{l}\text { No } \\
\text { de la } \\
\text { Cepa }\end{array}$ & $\begin{array}{l}\text { Color } \\
\text { del M icelio } \\
\text { A éreo }\end{array}$ & $\begin{array}{l}\text { Color } \\
\text { del Micelio } \\
\text { Vegetativo }\end{array}$ & $\begin{array}{l}\text { M orfología } \\
\text { de la Cadena } \\
\text { de Esporas }\end{array}$ & $\begin{array}{l}\text { Pigmento } \\
\text { M elanoide }\end{array}$ & $\begin{array}{l}\text { A specto } \\
\text { de la } \\
\text { Colonia }\end{array}$ \\
\hline 1 & Blanco & $\mathrm{SC}$ & $\mathrm{RF}$ & - & $P$ \\
\hline 2 & Blanco & SC & RF & - & $P$ \\
\hline 3 & Blanco & SC & $S$ & - & $P$ \\
\hline 4 & Blanco & SC & RF & + & $P$ \\
\hline 5 & Gris & SC & $S$ & + & $P$ \\
\hline 6 & Blanco & SC & RF & - & P \\
\hline 7 & Gris & SC & RF & - & $P$ \\
\hline 8 & Blanco & SC & RF & - & $P$ \\
\hline 9 & Blanco & SC & 5 & - & $P$ \\
\hline 10 & Blanco & SC & RF & - & $P$ \\
\hline 11 & Gris & SC & RF & - & $C$ \\
\hline 12 & Blanco & SC & $S$ & - & $P$ \\
\hline 13 & Gris & Negro & RF & + & $P$ \\
\hline 14 & Blanco & SC & $S$ & - & $P$ \\
\hline 15 & Blanco & SC & RF & $\begin{array}{ll}- \\
-\end{array}$ & $P$ \\
\hline 16 & Gris & MO & $S$ & + & $C$ \\
\hline 17 & Gris & MO & 5 & + & C \\
\hline 18 & Gris & MO & RF & - & C \\
\hline 19 & Blanco & SC & RF & + & $P$ \\
\hline 20 & Blanco & SC & $\mathrm{RF}$ & + & $P$ \\
\hline
\end{tabular}

$\begin{array}{llll}\text { RF } & \text { : Rectus flexibilis. } & \text { MO } & \text { : M arrón oscuro. } \\ \text { S } & : \text { Spira. } & \text { P } & \text { : Pulverulento. } \\ \text { SC } & : \text { Sin color. } & \text { C } & \text { : Coriácea. }\end{array}$


A. Tresierra A., M. E. Bendayán A. y M. García D.

\section{Cuadro 2}

Capacidad Antifúngica de las Cepas de Streptomyces estudiadas

\begin{tabular}{lcc}
\hline A ctividad antifúngica & No de cepas & Porcentaje \\
Presente & 3 & 15,0 \\
A usente & 17 & 85,0 \\
TOTAL & 20 & 100,0 \\
\hline
\end{tabular}

\section{Cuadro 3}

\section{E spectro Antibiótico de las tres cepas de Streptomyces con capacidad antifúngica}

\begin{tabular}{cl}
\hline № de cepa & \multicolumn{1}{c}{ Hongo sensible } \\
& \\
\hline 11 & Trichophyton rnentagrophytes \\
13 & Epidermophyton floccosum \\
19 & Trichophyton mentagrophytes \\
\hline
\end{tabular}

\section{DISCUSION}

L os organismos del género Streptomyces constituyen al rededor del $80 \%$ de la población de actinomicetos presentes en el suelo, aunque su ocurrencia numérica depende de la estación, vegetación, así como de otros factores ecológicos propios de la zona, Kuster, (1976).

L a profundidad, el contenido de agua y el tipo de suelo, influyen sobre la presencia de estas bacterias en el suelo; de allí que en este estudio, se consideró conveniente tomar muestras superficiales de suelo, ya que como lo expresa Kuster, E. 1976, el número de estas bacterias disminuye al aumentar la profundidad del suelo. Además, el citado investigador manifiesta que existen otros factores que se deben de considerar, tales como el aumento de la temperatura y la aireación, puesto que estimulan el crecimiento de estas bacterias filamentosas en el suelo.

Un aspecto que no se pudo controlar fue la reducción de la humedad, ya que las constantes precipitaciones fluvial es hacen que los suelos sean húmedos, lo cual afecta el desarrollé de los Streptornyces. Por otro lado, el laboreo del suelo 
le confiere una mejor aireación, actividad que incrementa el crecimiento de estas bacterias aerobias; por esta razón es que se consideró conveniente elegir muestras de suelos agrícolas.

A dicionalmente, Isizawa y A raragi, 1976, determinaron que la presencia de materia orgánica y las buenas condiciones nutritivas del suelo, favorecen el desarrollo de los actinomicetos; factores que también fueron considerados en el presente estudio.

En lo referente a la determinación de la actividad antimicótica de los cultivos aislados, en este estudio, al igual que el realizado por Burga, M.0 1969, cada cultivo fue probado por las técnicas de la estría en agar y de los bloques, teniendo en consideración que en ambos casos, cada cultivo se desarrolla en medios sólidos y la confirmación de la capacidad antibiótica se hizo mediante la técnica de los cilindros, ya que en esta, la síntesis de los antibióticos se realizó en cultivos líquidos agitados.

L os cultivos seleccionados presentaron zonas de inhibición que fluctuaban desde 10 a $26 \mathrm{~mm}$. hecho que se debe resaltar ya que (Waksman, 1961), el investigador que más se ha dedicado a este campo, con poca frecuencia encontré zonas de inhibición con tales dimensiones.

Alegría y Huarcaya en 1987, reportaron a este género bacteriano como uno de los más activos en la síntesis de antibióticos ya que mostraron poseer amplios espectros.

Por otro lado, Chávez, M. 1970, de un total de 345 cultivos de Streptornyces, sólo el $1.45 \%$ mostró poseer actividad antibiótica con amplios espectros antimicrobianos; sin embargo, en nuestro estudio, de un total de 20 cultivos, 3 de estos (15.0\%) mostraron actividad contra los hongos de prueba (Cuadro 2), pero al igual que Burga, M.O. 1969 y Requejo, V.H. 1965, sus espectros de acción fueron reducidos (Cuadro 3).

Al parecer, T. mentagrophytes es el agente causante de dermatomicosis más susceptible a la actividad antifúngica de Streptornyces, pero para poder concluir esto, consideramos necesario realizar estudios en los que se incluyan a un mayor número de cepas.

El hecho de haber aislado cultivos que produzcan grandes zonas de inhibición, resulta ser un hecho de gran importancia, más aún si se tiene en consideración que en estas pruebas sólo se han empleado medios de cultivo sencillos y no medios especiales u otros procesos (radiaciones o sustancias químicas adecuadas) que tienden a mejorar la capacidad de síntesis de antibióticos.

Rautenshtein, Y.1 1966, considera que todavía queda por estudiar sus acciones cualitativamente, ensayar mayor número de cepas y precisar, de ser posible, la naturaleza del principio activo, lo cual sería motivo de posteriores 
investigaciones. Además, es necesario contar con métodos de identificación de especies productoras de antibióticos que sean más rápidos y exactos.

\section{BIBLIOGRAFIA}

ALEGRIA, V.y J. HUARCAYA, 1987. Producción de antibióticos por cepas de actinomicetos aislados en suelos de cultivo. $X$ Congreso Latinoamericano de M icrobiología. Trujillo. 260 pp.

BURGA, M.0. 1969. Fórmula para un medio de estudio y aislamiento de Streptomyces. Tesis para optar el grado de Bachiller en Ciencias Biológicas. Universidad Nacional de Trujillo. 18 pp.

CHAVEZ, M. 1970. Agar glutamato: Medio para el aislamiento de Streptomyces. Tercer Congreso Peruano de M icrobiología y Parasitología. Trujillo. 125 pp.

------. 1976. Streptornyces del Suelo de Jardines de Trujillo. Tesis Doctoral. Universidad Nacional de Trujillo. 19 pp.

CURRAN, D. 1977. General Microbiology Laboratory Manual. A merican Elsevier Publishing Company. Oregon State U niversity. U nited States. 148 pp.

ISIZAWA, 5.; M. ARARAGI, 1976. Composition of actinomycetes population in soil, In Actinomycetes: The Boundary Microorganisms. APAIT 1. (cd) Toppan Company Limited. Tokio. 723 pp.

KUMATE, J. 1981. A ntibióticos y quimioterápicos. Segunda edición. M éndezCervantes S.A. M éxico. 343 pp.

KUSTER, E. 1976. Ecology and predominance of Streptomycetes. In: Actinomycetes: The boundary microorganisms. APAIT T. (ed). Toppan Company Limited. Tokio. 723 pp.

LOCCI, R. 1989. Streptomycetes and Related Genera. In: Bergey's M anual of Systematic Bacteriolog. WILLIAMS, 5.; SHARPE, E. and HOLT, J. (eds). The W illiam \& Wilkins. Baltimore/L ondon. USA. V ol. IV 2648 pp.

RAUTENSHTEIN, Y.I. 1966. Biology of antibiotic producing actinomycetes. Israel Program for Scientific Translations. Jerusalem. 322 pp. 
REQUEJO, V.H. 1965. Estudio Experimental de una cepa de Streptornyces aislada de una muestra de suelo e investigación de su actividad antibiótica. Tesis para optar el grado de Bachiller en Ciencias Biológicas. Universidad Nacional de Trujillo. 30 pp.

SHEARER, M.C. 1987. Methods for the Isolation of non-Streptomycetes actinomycetes. In: Developments in Industrial Microbiology. PIERCE, T. (cd). Elsevier Science Publishers Company Inc. 369 pp.

WAKSMAN, 5. 1961. The Actinomycetes. The William \& Wilkins Company. Baltimore. USA. Vol. 1. 296 pp. 